OPEN ACCESS

Edited by:

Zuhua $\mathrm{He}$

Shanghai Institute for Biological Sciences, Chinese Academy of

Sciences, China

Reviewed by:

Steven Michiel Driever,

Wageningen University, Netherlands

Hualing Mi,

Shanghai Institutes for Biological

Sciences, Chinese Academy of

Science, China

*Correspondence:

Jianchang Yang

jcyang@yzu.edu.cn

${ }^{\dagger}$ These authors have contributed equally to this work.

Specialty section:

This article was submitted to

Plant Physiology,

a section of the journal

Frontiers in Plant Science

Received: 08 October 2016

Accepted: 06 June 2017

Published: 20 June 2017

Citation:

Gu J, Zhou Z, Li Z, Chen Y, Wang Z,

Zhang $H$ and Yang $J(2017)$

Photosynthetic Properties and

Potentials for Improvement of

Photosynthesis in Pale Green Leaf

Rice under High Light Conditions.

Front. Plant Sci. 8:1082.

do: $10.3389 /$ fpls.2017.01082

\section{Photosynthetic Properties and Potentials for Improvement of Photosynthesis in Pale Green Leaf Rice under High Light Conditions}

\author{
Junfei Gu ${ }^{\dagger}$, Zhenxiang Zhou ${ }^{+}$, Zhikang Li, Ying Chen, Zhiqin Wang, Hao Zhang and \\ Jianchang Yang *
}

Jiangsu Key Laboratory of Crop Genetics and Physiology/Co-Innovation Center for Modern Production Technology of Grain Crops, Yangzhou University, Yangzhou, China

Light is the driving force of plant growth, providing the energy required for photosynthesis. However, photosynthesis is also vulnerable to light-induced damage caused by the production of reactive oxygen species (ROS). Plants have therefore evolved various protective mechanisms such as non-photochemical quenching (NPQ) to dissipate excessively absorbed solar energy as heat; however, photoinhibition and NPQ represent a significant loss in solar energy and photosynthetic efficiency, which lowers the yield potential in crops. To estimate light capture and light energy conversion in rice, a genotype with pale green leaves (pgl) and a normally pigmented control (Z802) were subjected to high (HL) and low light (LL). Chlorophyll content, light absorption, chloroplast micrographs, abundance of light-harvesting complex (LHC) binding proteins, electron transport rates (ETR), photochemical and non-photochemical quenching, and generation of ROS were subsequently examined. Pgl had a smaller size of light-harvesting chlorophyll antenna and absorbed less photons than Z802. NPQ and the generation of ROS were also low, while photosystem II efficiency and ETR were high, resulting in improved photosynthesis and less photoinhibition in pg/ than Z802. Chlorophyll synthesis and solar conversion efficiency were higher in pgl under $\mathrm{HL}$ compared to $\mathrm{LL}$ treatment, while Z802 showed an opposite trend due to the high level of photoinhibition under HL. In Z802, excessive absorption of solar energy not only increased the generation of ROS and NPQ, but also exacerbated the effects of increases in temperature, causing midday depression in photosynthesis. These results suggest that photosynthesis and yield potential in rice could be enhanced by truncated light-harvesting chlorophyll antenna size.

Keywords: chlorophyll, electron transport rate, light-harvesting chlorophyll antenna, non-photochemical quenching, reactive oxygen species, photosynthesis

\section{INTRODUCTION}

Global agriculture is facing unprecedented challenges, with a predicted increase in primary foodstuffs of $85 \%$ required by 2050 , relative to 2013 (Ray et al., 2013). In addition, yield improvements are beginning to slow or stagnate with the Green Revolution reaching its biological limits. Accordingly, photosynthesis, which has shown few improvements in crop breeding, remains 
the key to increased genetic yield potential (Long et al., 2015). Reducing the energy losses during photosynthesis could help improve solar energy conversion efficiency, thereby boosting crop yields (Gu et al., 2014; Furbank et al., 2015; Yin and Struik, 2015).

Non-photochemical quenching (NPQ) is a major cause of solar energy conversion efficiency loss, not least because $\mathrm{C}_{3}$ leaf photosynthesis is saturated at $\sim 25 \%$ maximum sunlight (Long et al., 2006). The energy of irradiated light is therefore often much higher than the demand for photosynthetic metabolism of NADPH and ATP (Melis, 1999; Niyogi, 2000; Miyake et al., 2005; Yamori and Shikanai, 2016). Excess excitation of plant photosystems results in over excitation of the reaction center, causing chlorophyll molecules to attain a triple state, ${ }^{3} \mathrm{P} 680^{*}$ (Hideg et al., 1998). ${ }^{3} \mathrm{P} 680^{*}$ reacts rapidly with $\mathrm{O}_{2}$, resulting in production of deleterious singlet $\mathrm{O}_{2}\left({ }^{1} \mathrm{O}_{2}\right)$ (Vass and Cser, 2009), which oxidatively degrades $D_{1}$ protein, a PSII reaction center protein, inactivating PSII (Krieger-Liszkay et al., 2008). The PSII reaction center is so vulnerable to light-induced damage that it has to be rebuilt approximately once every $30 \mathrm{~min}$ (Foyer and Shigeoka, 2011). Furthermore, inherent limitations in the capacity for electron transport through the cytochrome $b_{6} / f$ complex lead to the production of photoexcited $\mathrm{Chl},{ }^{1} \mathrm{Chl}^{*}$, and its triplet state, ${ }^{3} \mathrm{Chl}{ }^{*}$, causing ${ }^{1} \mathrm{O}_{2}$ accumulation in the thylakoid membranes (Macpherson et al., 1993; Telfer, 2014), which stimulates peroxidation and degradation of membrane bilayers. To protect PSII from excess radiation, plants dissipate excessive energy as heat via the xanthophyll cycle, which involves de-epoxidase-induced catalysis of the xanthophyll pigment violaxanthin to zeaxanthin. This photoprotection process is referred to as NPQ of chlorophyll fluorescence (Niyogi et al., 1998; Miyake et al., 2005; Yamori and Shikanai, 2016), and represents a significant loss of solar energy (Ort et al., 2015).

During the photosynthetic process, a minimum of eight photons are required to assimilate one molecule of $\mathrm{CO}_{2}$ : (i) assimilation of $1 \mathrm{~mol} \mathrm{CO}_{2}$ in the Calvin-Benson cycle requires 2 mol NADPH; (ii) reduction of $\mathrm{NADP}^{+}$to $\mathrm{NADPH}$ involves the transfer of 2 electrons; and (iii) movement of $1 \mathrm{~mol}$ of electron along the linear electron transport chain through PSII and PSI requires $1 \mathrm{~mol}$ photon absorption by each photosystem. Moreover, taking into account the spectrum of sunlight that is used for photosynthesis as well as the absorption efficiency of the leaves, the energy in natural solar radiation and the amount of $\mathrm{CH}_{2} \mathrm{O}$ in glucose, the maximum solar energy conversion efficiency can reach up to $12.3 \%$ (Yin and Struik, 2015). However, in annual crops, the typical solar energy conversion efficiency is very low, usually $<1 \%$ (de Groot, 2008). Thus, huge energy losses occur in plant photosystems compared to the theoretical maximum with actual solar energy conversion efficiency, in which the fraction of energy loss due to $N P Q$ increases with increasing solar radiation, reaching up to $60 \%$ of captured sunlight under full sunlight (Yin and Struik, 2015). One way to increase solar conversion efficiency and reduce $N P Q$ is to reduce antenna size of the photosystems. If too large, the antennae have been shown to trap more light than can be used. Thus, if plants had fewer light-harvesting pigments (e.g., chlorophyll and carotenoids) per photosystem, solar energy conversion efficiency could be greatly improved (Melis, 2009; Ort et al., 2011, 2015; Long et al., 2015). This suggests that there is potential to reduce the size of chlorophyll antennae, thereby lowering energy waste through NPQ and improving solar energy conversion efficiency.

In the crop canopy, reducing the chlorophyll content would not only mitigate efficiency losses associated with NPQ but also allow greater transmittance of light into lower layers, thus improving canopy light distribution and canopy photosynthesis (Pettigrew et al., 1989; Ort et al., 2011; Gu et al., 2017). In green alga, the tla mutant was found to have improved photosynthetic solar energy conversion efficiency and productivity by up to three-fold compared to the wild-type due to the truncated chlorophyll antenna size of its photosystems (Melis et al., 1998; Polle et al., 2003; Melis, 2009). In higher plants, decreased leaf chlorophyll content has also been shown to be advantageous in terms of photosynthetic efficiency in rice (Gu et al., 2017) and soybean (Pettigrew et al., 1989). A decrease in leaf chlorophyll content could also be evolutionarily advantageous in high light and high temperature environments (Tardy et al., 1998), since lowering leaf chlorophyll content has also been shown to act as a photoprotection mechanism, mitigating the damaging effects of high radiation and high leaf temperature in wild grasses and cereal landraces adapted to semi-arid environments (Havaux and Tardy, 1999; Zaharieva et al., 2001; Royo et al., 2014). Under long-term acclimation to high light environments, plants adjust to the environment by increasing antioxidant production and decreasing light harvesting antenna size through regulated gene expression (Foyer and Noctor, 2009). However, in rice, it is unknown whether and to what extent photo-oxidative stress is relieved and solar energy conversion efficiency improved via selection of a genotype with reduced chlorophyll content. Accordingly, the benefits at the canopy level also remain unknown.

Previous research aimed at improving photosynthesis has focused mainly on optimization of the Calvin cycle, which assimilates and reduces carbon dioxide conversion to carbohydrates. Approaches have included designing more efficient Rubisco, increasing mesophyll conductance, introducing a $\mathrm{CO}_{2}$-concentrating mechanism in $\mathrm{C}_{3}$ crops, and shortcircuiting photorespiration (Mueller-Cajar and Whitney, 2008; Uehlein et al., 2008; Whitney and Sharwood, 2008; Maurino and Peterhansel, 2010; von Caemmerer et al., 2012). However, less attention has been paid to optimization of light capture and solar energy conversion during light reactions (Ort et al., 2015). In this study, we used the early indica rice variety Zhefu 802 and a pale green leaf genotype originating from Zhefu 802 to examine the hypothesis that truncated light-harvesting chlorophyll antenna size could improve photosynthesis in rice. Chlorophyll content, light absorption, chloroplast development, electron transport, photochemical and non-photochemical quenching, and generation of ROS were examined in both genotypes to (i) investigate photosynthetic efficiency in the chlorophyll-deficient and normal genotype; (ii) examine the effects of high light intensity on oxidative stress in the two genotypes; and (iii) determine the relationship between chlorophyll content and diurnal variation in photosynthesis under field conditions. The results would provide valuable insight into the mechanisms of 
photoprotection and increased photosynthetic efficiency with truncated light-harvesting chlorophyll antenna size, helping development of strategies for improved grain yield potential in rice.

\section{MATERIALS AND METHODS}

\section{Plant Material and Growth Conditions}

The $p g l$ genotype with pale green leaves was generated by radiation from the early indica rice variety Zhefu 802 (Z802). In this study, both the $p g l$ and Z802 genotype were used to examine the effects of chlorophyll concentration on photosynthetic characteristics.

Experiments were conducted at the research farm of Yangzhou University, Jiangsu Province, China $\left(32^{\circ} 30^{\prime} \mathrm{N}, 119^{\circ} 30^{\prime} \mathrm{E}\right)$. The soil was sandy loam (Typic Fluvaquent, Etisol) with $23.2 \mathrm{~g} \mathrm{~kg}^{-1}$ organic matter, $95.2 \mathrm{mg} \mathrm{kg}^{-1}$ alkali-hydrolyzable $N, 22.5 \mathrm{mg} \mathrm{kg}^{-1}$ Olsen-P, and $82.6 \mathrm{mg} \mathrm{kg}^{-1}$ exchangeable K. Seeds were first sown in the paddy field on 12 May 2015.

In the pot experiment, seedlings were transplanted to pots (30 $\mathrm{cm}$ in height and $25 \mathrm{~cm}$ in diameter, $14.7 \mathrm{~L}$ in volume) on 13 June 2015. Each pot was filled with $20 \mathrm{~kg}$ of sandy loam soil, three hills per pot and two seedlings per hill. On the day of transplanting, $0.5 \mathrm{~g}$ of $\mathrm{KH}_{2} \mathrm{PO}_{4}$ was mixed with the soil in each pot as basal fertilizer. The nitrogen rate was $3.6 \mathrm{~g}$ urea per pot. The urea was applied at pre-transplanting (1 day before transplanting), early tillering ( $\sim 7$ days after transplanting), and the panicle initiation stage (40 days after transplanting) at rates of 50, 20, and $30 \%$, respectively. At the 5th leaf stage, plants were moved to climate chambers under the following photosynthetic photon flux densities (PPFD): $\sim 150 \mu \mathrm{mol} \mathrm{m} \mathrm{m}^{-2} \mathrm{~s}^{-1}$ (low light, LL) and $1,000 \mu \mathrm{mol} \mathrm{m}^{-2} \mathrm{~s}^{-1}$ (high light, HL) at the canopy level during the light period. All other environmental factors were kept the same. The temperature in the climate chambers was set at $28^{\circ} \mathrm{C}$ for a $12 \mathrm{~h}$ light period and $23^{\circ} \mathrm{C}$ for a $12 \mathrm{~h}$ dark period. $\mathrm{CO}_{2}$ was set at $380 \mu \mathrm{mol} \mathrm{mol}{ }^{-1}$ and the relative humidity at $65 \%$. The pots were kept in the climate chambers for 20 days up until expansion of the 7th leaf. The 7th leaf was then sampled for physiological analysis, having fully acclimated to the relative light environment.

In the field experiment, seedlings were transplanted to the field on 13 June 2015 at a hill spacing of $25 \times 15 \mathrm{~cm}$ with two seedlings per hill. P ( $30 \mathrm{~kg} \mathrm{ha}^{-1}$ as single superphosphate) and $\mathrm{K}$ ( $40 \mathrm{~kg} \mathrm{ha}^{-1}$ as $\mathrm{KCl}$ ) were applied and incorporated just before transplanting as basal fertilizer. Three levels nitrogen $(0,120$, or $240 \mathrm{~kg} \mathrm{~N} \mathrm{ha}{ }^{-1}$ ) in the form of urea was applied. The time and proportion of urea application were the same as in the pot experiment. The experiment followed a split-plot design with three replicates per treatment, using nitrogen as the main plot and genotype as the sub-plot variable. Each plot was $7 \times 6 \mathrm{~m}$. Weeds were controlled by a combination of chemical and manual methods, and insects were controlled chemically.

\section{Leaf Optical Measurements}

Leaf optical measurements were conducted using a double integrating sphere system. An ISP-REF integrating sphere (Ocean Optics, Inc., Dunedin, Florida, USA) with a built-in collimated light source and a gloss-trap combined with a FOIS-1 fiber optic integrating sphere (Ocean Optics) were used. Both spheres were connected via fiber optic bundles to a S2000 UV-VIS-shortwave NIR spectroradiometer (Ocean Optics) with a resolution of $\sim 0.5$ $\mathrm{nm}$. They were aligned using a rack-and-pinion slide (NT61-285, Edmund Industrial Optics, Barrington, New Jersey, USA) with a platform for each sphere. By clamping a leaf between the two integrating spheres, simultaneous measurements of leaf spectral reflectance $(\mathrm{R})$ and transmittance $(\mathrm{T})$ were possible. Absorptance (A) was calculated as $\mathrm{A}=1-(\mathrm{R}+\mathrm{T})$.

\section{Electron Microscopy}

Leaf sections $\sim 1-2 \mathrm{~mm}^{2}$ were cut from the middle of newly expanded leaves using two razor blades, fixed in $2.5 \%$ glutaraldehyde $\left(0.1 \mathrm{~mol} \mathrm{l}^{-1}\right.$ phosphate buffer, $\left.\mathrm{pH} 7.4\right)$ then postfixed with $2 \%$ osmium tetroxide. Specimens were dehydrated in a graded acetone series and embedded in Epon 812. Samples were then dissected using a Power Tome-XL ultramicrotome, stained with $2 \%$ uranyl acetate and examined with a CM 100 transmission electron microscope (Philips, Netherlands).

\section{Rapid Light Curve Measurements}

Fluorescence measurements were performed using a MINIPAM-II fluorometer (Walz, Germany). Rapid light curves (RPCs) were initiated at light intensities of 26, 46, 67, 94, 131, 199, 298, $441,661,860,1,203$, and $1,568 \mu \mathrm{mol} \mathrm{m}^{-2} \mathrm{~s}^{-1}$, at a duration of $30 \mathrm{~s}$ illumination per light intensity. At each light level, fluoresce signal $F$ and maximum fluorescence after a saturating light pulse $F_{\mathrm{m}}^{\prime}$ were recorded, and the effective quantum yield of PSII $\left(\Phi_{\text {PSII }}\right)$, photochemical quenching $(q P)$, and non-photochemical quenching (NPQ) calculated as follows (Genty et al., 1989; Bilger and Björkman, 1990; Ralph and Gademann, 2005):

$$
\begin{array}{r}
\Phi_{\mathrm{PSII}}=\Delta F / F_{\mathrm{m}}^{\prime}=\left(F_{\mathrm{m}}^{\prime}-F\right) / F_{\mathrm{m}}^{\prime} \\
q P=\left(F_{\mathrm{m}}^{\prime}-F\right) /\left(F_{\mathrm{m}}^{\prime}-F_{o}\right) \\
N P Q=\left(F_{\mathrm{m}}-F_{\mathrm{m}}^{\prime}\right) / F^{\prime}{ }_{\mathrm{m}}
\end{array}
$$

Changes in the electron transport rate (ETR; $\mu$ mol electron $\mathrm{m}^{-2}$ $\mathrm{s}^{-1}$ ) with increasing photosynthetic active radiation (PAR, 0$1,568 \mu \mathrm{mol} \mathrm{m}{ }^{-2} \mathrm{~s}^{-1}$ ) were used to generate the RLCs. Relative ETR ( $r$ ETR) represents a relative measurement of electron transport through the photochemical reactions leading to carbon fixation:

$$
r \mathrm{ETR}=\mathrm{PAR} \times \Phi_{\text {PSII }} \times 0.5 \times \chi
$$

where 0.5 is a multiplication factor of two quanta of light required for the transport of one electron, and $\chi$ is the fraction of incident quanta absorbed by leaves from genotype Z802 or pgl.

Photosynthetic parameters were estimated from the RLCs using the equation of Platt et al. (1980):

$$
P=P_{\mathrm{s}}\left[1-\exp \left(-\alpha E / P_{\mathrm{s}}\right)\right] \exp \left(-\beta E / P_{\mathrm{s}}\right)
$$

In the absence of photoinhibition $(\beta=0)$, the function becomes a standard rectangular hyperbola, with an asymptotic maximum 
$r$ ETR value (Harrison and Platt, 1986). The following simplified equation can be applied:

$$
P=P_{\mathrm{m}}\left[1-\exp \left(-\alpha E / P_{\mathrm{m}}\right)\right]
$$

where $P_{\mathrm{s}}$ is a scaling parameter defined as the maximum potential $r$ ETR, $P_{\mathrm{m}}$ is the photosynthetic capacity at saturating light, $\alpha$ is the photosynthetic efficiency measured by the initial slope of the RLC before the onset of saturation, $E$ is the light density, and $\beta$ characterizes the slope of the RLC where PSII declines (Henley, 1993). $r \mathrm{ETR}_{\max }$ (relative electron transport maximum) and $E_{k}$ (minimum saturating irradiance) were estimated as:

$$
\begin{array}{r}
r \mathrm{ETR}_{\max }=P_{\mathrm{s}}[\alpha /(\alpha+\beta)][\beta /(\alpha+\beta)]^{\beta / \alpha} \\
E_{k}=E T R_{\max } / \alpha
\end{array}
$$

For curve fitting, iterative non-linear least square regression was carried out using the GAUSS method in PROC NLIN of SAS (SAS Institute Inc., Cary, NC, USA).

\section{Quantitative Analysis of Protein by the Isobaric Tags for Relative and Absolute Quantification (iTRAQ)}

The procedure of quantitative proteomic analysis was essentially identical as described previously ( $\mathrm{Yu}$ et al., 2016), including the steps of protein extraction, in solution and iTRAQ labeling, strong cation exchange, and LC-MS/MS. For protein identification, it was performed by using Mascot search engine (Matrix Science, London, UK; version 2.3.02) against database containing rice sequences. The charge states of peptides were set to +2 and +3 . Specifically, an automatic decoy database search was performed in Mascot by choosing the decoy checkbox in which a random sequence of database is generated and tested for raw spectra as well as the real database. To reduce the probability of false peptide identification, only peptides at the $95 \%$ confidence interval by a Mascot probability analysis greater than "identity" were counted as identified. And each confident protein identification involves at least one unique peptide. For protein quantitation, it was required that a protein contains at least two unique peptides. The quantitative protein ratios were weighted and normalized by the median ratio in Mascot. Therefore, the proteins with $p<0.05$, and fold-change ratios $\geq 1.5$ or $\leq 0.67$ were considered as significant.

\section{ROS Detection by Fluorescence Microscopy}

Superoxide radicals were detected by staining with $10 \mu \mathrm{M}$ dihydroethidium (DHE) (Yamamoto et al., 2002). As a negative control, transections of leaves were incubated with $1 \mathrm{mM} \mathrm{N}_{3} \mathrm{Na}$ (peroxidase inhibitor). Fluorescent images were captured using an Axio Imager D2 microscope (Zeiss, Oberkochen, Germany) with DHE fluoresces red (540 nm excitation, $590 \mathrm{~nm}$ emission).

\section{Analysis of Lipid Peroxidation and Antioxidant Enzyme Activity}

The content of malondialdehyde (MDA), a sign of lipid peroxidation, was estimated by measuring the concentration of thiobarbituric acid reactive substances (TBARS) (Dhindsa et al., 1981). A superoxide dismutase (SOD) activity assay was conducted based on the inhibition of the photoreduction of nitroblue tetrazolium (NBT) as described by Giannopolitis and Ries (1977). One unit of SOD activity was defined as the amount of enzyme causing $50 \%$ inhibition of the reaction in the absence of an enzyme under these conditions. A peroxidase (POD) activity assay was conducted based on the conversion of guaiacol to tetraguaiacol monitored at $470 \mathrm{~nm}$, as described by Chance and Maehly (1955). Catalase (CAT) activity was measured according to the method of Aebi (1983) with some modifications. The CAT reaction mixture contained $25 \mathrm{mM}$ sodium phosphate buffer ( $\mathrm{pH} 7.0$ ) and $40 \mathrm{mM} \mathrm{H}_{2} \mathrm{O}_{2}$. The reaction was initiated by adding enzyme extract, and the change in absorbance of the reaction solution at $240 \mathrm{~nm}$ recorded every $20 \mathrm{~s}$.

\section{Thermal Imaging of the Rice Canopy}

The temperature of leaves in the rice canopy was determined using an FLIR ThermaCAM ${ }^{\mathrm{TM}}$ S65 system (FLIR Systems Inc., Portland, OR. USA) with a wide-angle camera lens (18 mm IRLENS), the spectral and detectable temperature ranges of which are $7.5-13 \mathrm{~mm}$ and -40 to $1,500^{\circ} \mathrm{C}$, respectively. Temperature differences of $<0.06^{\circ} \mathrm{C}\left(30^{\circ} \mathrm{C}, 50 \mathrm{~Hz}\right)$ can be detected. Data were analyzed using Therma CAM Researcher Pro 2.7 software (FLIR Systems Inc., Portland, USA).

\section{Photosynthesis Measurements}

For light-saturated photosynthesis, the middle parts of fully expanded leaves were measured using a portable open gas exchange system (Li-6400, Li-COR Inc., Lincoln, NE, USA) with a $2 \times 3 \mathrm{~cm}$ leaf chamber (LI-6400-02 LED, Li-COR Inc., Lincoln, NE, USA) at an ambient $\mathrm{CO}_{2}$ concentration, similar to Cui et al. (2016), but with light intensity set at $1,500 \mu \mathrm{mol}$ $\mathrm{m}^{-2} \mathrm{~s}^{-1}$, leaf temperature set at $25^{\circ} \mathrm{C}$. For measurements of diurnal variation of the net photosynthesis, measurements were taken on clear days around flowering stage with natural fluctuation of air temperature and vapor pressure deficit. The PPFD used for each assessment was provided by the artificial light source (LI-6400-02 LED, Li-COR Inc., Lincoln, NE, USA), which was set to provide the same PPFD as solar intensity that was tracked by an external light sensor of LI-6400 near leaf chamber.

\section{RESULTS}

\section{Chlorophyll Content, Biomass, Photosynthesis, Anatomical Structure and the Effects on Light Absorption}

The pale green leaves of the $p g l$ genotype (Figure 1) were consistent with its significantly lower chlorophyll content (0.75 $\mathrm{mg} \mathrm{g}^{-1} \mathrm{FW}$ under LL and $1.20 \mathrm{mg} \mathrm{g}^{-1} \mathrm{FW}$ under HL; Figure 2) compared to Z802 (2.79 and $2.18 \mathrm{mg} \mathrm{g}^{-1}$, respectively). Under LL and HL, the chlorophyll content of $p g l$ was 27 and $55 \%$ that of Z802, respectively. Compared with LL treatment, the chlorophyll content of Z802 decreased by $22 \%$ under HL. In contrast, an increase of $60 \%$ was observed in $p g l$. The ratio of chlorophyll $a$ to $b(\mathrm{Chl} a / b)$ were greatly improved 




FIGURE 1 | Genotype Z802 (right) and pg/ (left) at the seedling stage.

from 3.6 to 7.0 and 2.6 to 9.6 for LL and HL treatments, respectively, when compare chlorophyll in Z802 with in $p g l$ (Figure 2).

There were not significant differences in biomass between two genotypes in LL treatment, while in HL treatment, the biomass of $p g l$ is significantly higher than Z802 (Figure 2). The lightsaturated photosynthesis is much higher in $p g l$ than in Z802 in HL treatment. When compared LL with HL treatments, the lightsaturated photosynthesis is decreased for Z802, but increased for $p g l$ (Figure 2). Negative correlations between chlorophyll content and biomass and light-saturated photosynthesis could be found in Figure 2, especially for the HL treatment. For the field experiment, the yield, yield components, and biomass of Z802 and $p g l$ in the field experiment also indicate a potential for production improvements by a smaller antenna size (Table S1).

Anatomical structure was also influenced by light (Figure 3). Leaf thickness was greatly improved with increasing light intensity in both genotypes from $87.87 \pm 7.51$ to 112.37 $\pm 9.24 \mu \mathrm{m}$ in $\mathrm{Z} 802$ under LL and HL, respectively, and from $82.65 \pm 4.0$ to $110.3 \pm 8.12 \mu \mathrm{m}$ in $p g l$, respectively. Increasing leaf thickness also resulted in a corresponding increase in leaf dry matter per unit area (LMA) from $30.5 \pm 2.8$ under $\mathrm{LL}$ to $36.9 \pm 2.7 \mathrm{~g} \mathrm{~m}^{-2}$ under $\mathrm{HL}$ in $\mathrm{Z} 802$, and from $25.2 \pm 1.0$ to $32.0 \pm 2.4 \mathrm{~g} \mathrm{~m}^{-2}$ in $\mathrm{pgl}$, respectively.

Although, the chlorophyll content was significantly lower in the $p g l$ genotype, the chloroplasts and grana were normal in both genotypes in terms of size and grana stacking (Figure 4). Comparisons of the chlorophyll micrographs revealed more osmophilic bodies in Z802 than pgl, especially under HL. This suggests disruption of the granum thylakoids in Z802 and a possible effect on chloroplast function due to photoinhibitory damage under HL.

Compared with the significant differences in leaf chlorophyll content (Figure 2), the differences in leaf spectral absorptance rates were comparatively small (Figure 5). In Z802, leaf spectral absorptance was comparable between LL and HL treatment, with leaves adapted to LL absorbing more photons than those adapted to HL. In contrast, an opposite trend was observed in pgl. These differences in light absorption might be due to the changes in chlorophyll content shown in Figure 2. For genotype Z802, the absorption rates were 0.898 and 0.883 at LL and HL treatments, respectively. For genotype $p g l$, the absorption rates were 0.808 and 0.846 at LL and HL treatments, respectively.

\section{Electron Transport Rates and the Solar Energy Conversion Efficiency}

Figure 6A indicates the photosynthetic electron transport rates of Z802 and pgl under different actinic light with HL and LL treatment. The curves showed a linear increase under limited light followed by a plateau when the photosynthetic pathway became saturated. The average $r$ ETR of the $p g l$ genotype across different light intensities was $42 \%$ higher than that of Z802, with the two genotypes responding differently to light. Leaves of Z802 had a higher $r$ ETR under LL than HL, with an opposite tendency in pgl. In Figure 6A, fitted curves are plotted with a dotted line, showing very close agreement with the actual data points $\left(R^{2}>99 \%\right)$. Estimated $r \mathrm{ETR}_{\max }, E_{k}$, and $\alpha$ values are also given in the RLCs of Z802 under LL. Since there was no apparent down-regulation of the RLCs, $\beta$ was set at 0 in the curve fitting. The resulting parameters estimated from curvefitting are listed in Table 1. The maximum electron transport $r \mathrm{ETR}_{\max }$ of $p g l$ was 1.8 times that of Z802 as was the average $E_{k}$ at $687.0 \mu \mathrm{mol}$ photons $\mathrm{m}^{-2} \mathrm{~s}^{-1}$. The substantially higher $r \mathrm{ETR}_{\max }$ and $E_{k}$ values suggest that the $p g l$ genotype is able to maintain a higher photosynthetic electron transport capacity. Furthermore, the photosynthetic capacity of $p g l$ improved under HL, unlike Z802, which performed better under LL.

Figure 6B shows the efficiency of photosystem II photochemistry, $\Phi_{P S I}$, in response to different actinic light. This parameter measures the proportion of light absorbed by chlorophyll associated with PSII and used in photochemistry, providing a measure of the rate of linear electron transport, and therefore, an indication of overall photosynthesis. $\Phi_{P S I I}$ decreased with increasing PAR, and was higher in $p g l$ than Z802 under all light intensities. Moreover, in $p g l$, PSII efficiency was generally higher under HL, unlike Z802, which was more efficient under LL. Photochemical $(q P$, Figure 6C) and non-photochemical quenching parameters $(N P Q$, Figure 6D) describe the relative effects of the energy dissipation pathway. $q P$ gives an indication of the proportion of PSII reaction centers that are open, while $N P Q$ measures energy flow into heat associated with xanthophyll cycle activity. Quenching coefficients plotted as a function of PAR showed a clear increase in NPQ and a steady decline in $q P$ with increasing irradiance. $N P Q$ in the Z802 genotype was nearly two times greater than that in $p g l$ with increasing light. Moreover, the extent of decline in $q P$ was considerably smaller in $p g l$ than Z802 with increasing PAR. Overall, the RLCs and RLC-derived parameters suggest high photon-electron conversion efficiency and reduced nonphotochemical quenching in $p g l$, thereby lowering energy losses. 



Light treatment

LL

Light treatment

FIGURE 2 | Chlorophyll content (A,B), biomass (C), light-saturated photosynthesis (D) for Z802 and pgl from high (HL) and low light (LL) adapted plants. Data represent the means of three replicates per treatment \pm standard deviation. The photosynthesis was measured at light intensity of $1,500 \mu \mathrm{mol} \mathrm{m} \mathrm{m}^{-2} \mathrm{~s}^{-1}$, temperature of $25^{\circ} \mathrm{C}$ with Li-6400.


FIGURE 3 | Light micrographs of chloroplasts under low (LL; A,B) and high light treatment (HL; C,D) in Z802 (A,C) and pgl (B,D). Bars = $50 \mu \mathrm{m}$.

\section{The Size of Light-Harvesting Chlorophyll}

\section{Antenna}

Light energy is captured by large, discrete complexes of chlorophyll molecules bound to proteins and embedded in the thylakoid membranes. The majority of the chlorophyll molecules in a photosystem make up chlorophyll antenna. The antenna contains light-harvesting complexes. The relative abundance of LHC-binding proteins (Figure 7) and chlorophyll content 



FIGURE 4 | Electron micrographs of chloroplasts under low (LL; A,B) and high light treatment (HL; C,D) in Z802 (A,C) and pg/ (B,D). Bars = $1 \mu$ m. Th, thylakoid lamellae; OB, osmophilic body; S, starch.

(Figure 2) indicated a truncated light-harvesting chlorophyll antenna size in $p g l$. This is also confirmed by the higher Chl $a / b$ in $p g l$, as chlorophyll $a$ is tend to locate in the reaction center, while chlorophyll $b$ is tend to locate in antenna. The binding proteins of LHC of photosystem I (LHCI) are Lhca1, Lhca2, Lhca3, and Lhca4. The binding proteins of LHC of photosystem II (LHCII) are Lhcb1, Lhcb2, Lhcb3, Lhcb4, Lhcb5, and Lhcb6 (Figure 7).

\section{Generation of ROS and Photoinhibitory Damage under High Irradiance}

In vivo detection of ROS in the leaves was carried out using a fluorescence microscope (Figure 8). To observe $\mathrm{O}_{2}^{-}$production, DHE, which is specific for this anion, was used as a probe (Zhao et al., 2003). DHE is also considered a marker of cell death, showing higher fluorescence signals in the zone around epidermal cells and vascular bundles (Rodríguez-Serrano et al., 2006; Figure 8). However, differences in fluorescence signals from mesophyll cells, indicating the location of chloroplasts, were found between the two genotypes (Figure 8). Fluorescence signal intensities under ZEN imaging were 95.0 and 69.5 for Z802 and $p g l$ in the negative control (Figures 8A,B), respectively, compared with 242.7 and 149.1 for Z802 and pgl under LL

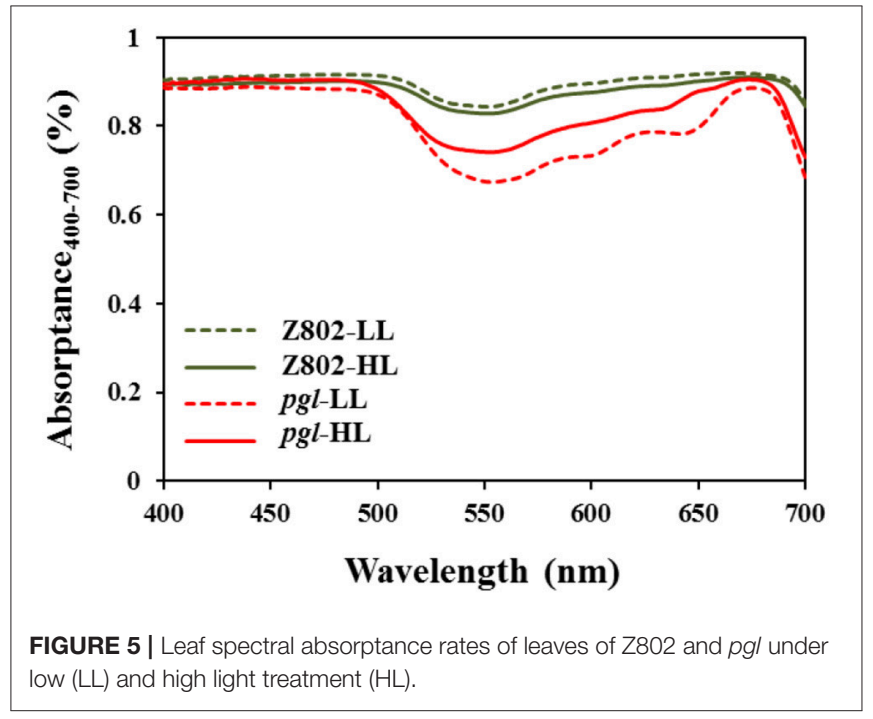

(Figures 8C,D), and 455.2 and 283.0 for Z802 and $p g l$ under HL, respectively (Figures 8E,F). These values combined with the ROS imaging data suggest that $\mathrm{O}_{2}^{-}$was depleted by $\mathrm{N}_{3} \mathrm{Na}$ in the 

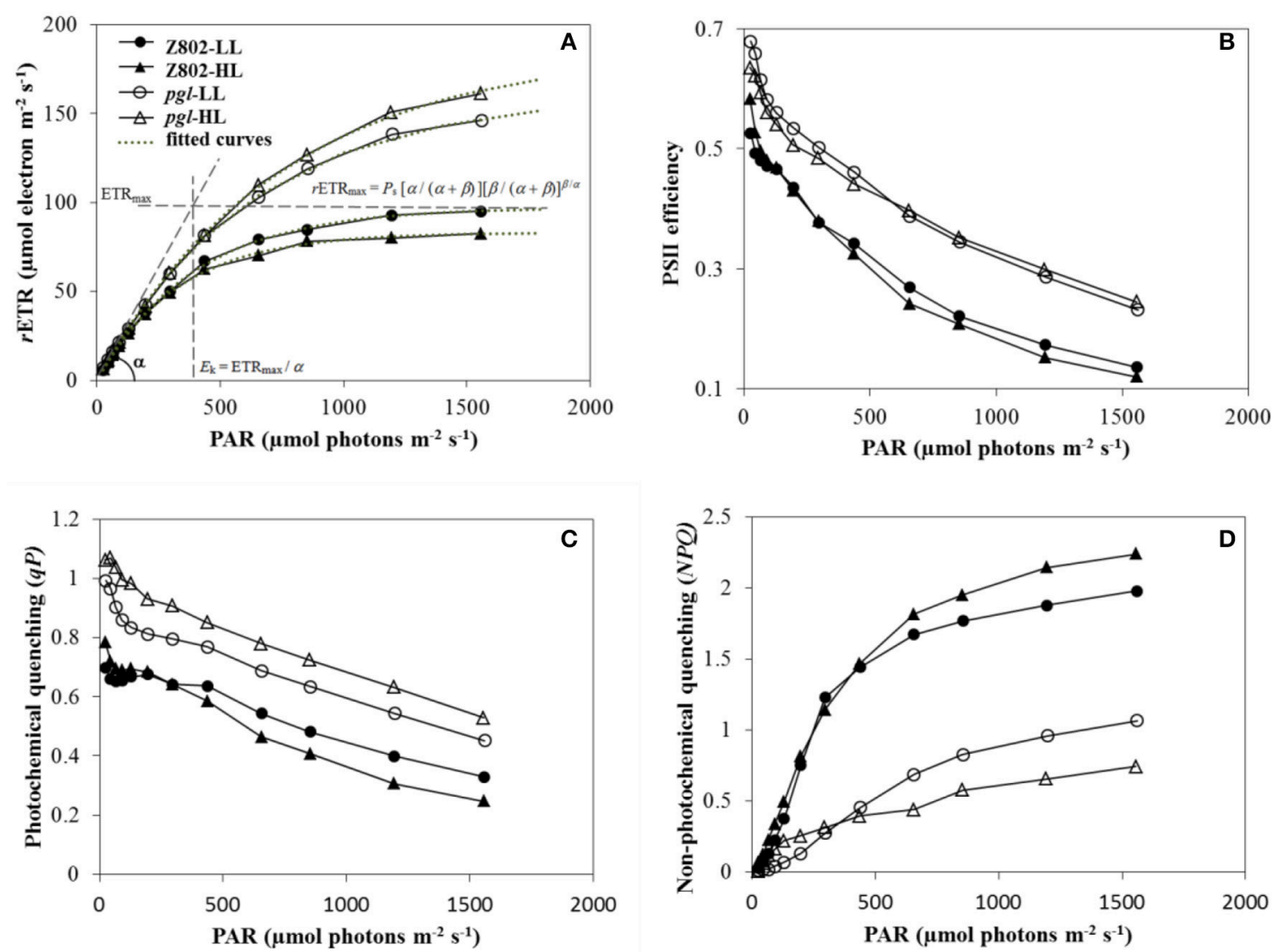

FIGURE 6 | (A) Rapid light curves (RLC) of Z802 and pgl under high (HL) and low light treatment (LL). The relative electron transport rate ( $r E T R)$ is plotted against PAR irradiance ( $\mu \mathrm{mol}$ photons $\mathrm{m}^{-2} \mathrm{~s}^{-1}$ ). Fitted curves are plotted with a dotted line, and the $r E T R \max , E_{k}$, and $\alpha$ are displayed in the RLCs of Z802 under LL. (B) PSII efficiency $\left(\Phi_{\mathrm{PSII}}\right)$, (C) photochemical quenching $(q P)$, and (D) non-photochemical quenching (NPQ) derived from the RLCs under high (HL) and low light (LL) in Z802 and $p g l$ as a function of PAR.

TABLE 1 | Estimated parameters from rapid light curves for Z802 and pgl under low (LL) and high light $(\mathrm{HL})$ by curve fitting.

\begin{tabular}{|c|c|c|c|}
\hline $\begin{array}{l}\text { Genotype- } \\
\text { treatment }\end{array}$ & $\alpha$ & $\begin{array}{c}r E T R_{\max }(\mu \mathrm{mol} \\
\left.\mathrm{e}^{-} \mathrm{m}^{-2} \mathrm{~s}^{-1}\right)\end{array}$ & $\begin{array}{c}E_{k}(\mu \mathrm{mol} \text { photons } \\
\left.\mathrm{m}^{-2} \mathrm{~s}^{-1}\right)\end{array}$ \\
\hline Z802-LL & $0.246 \pm 0.004^{\mathrm{Bb}}$ & $97.2 \pm 0.8^{A b}$ & $395.1^{A b}$ \\
\hline Z802-HL & $0.253 \pm 0.004^{\mathrm{Aa}}$ & $83.1 \pm 0.7^{\mathrm{Bb}}$ & $328.5^{\mathrm{Bb}}$ \\
\hline pgl-LL & $0.255 \pm 0.003^{\mathrm{Aa}}$ & $160.9 \pm 1.3^{\mathrm{Ba}}$ & $631.0^{\mathrm{Ba}}$ \\
\hline$p g /-H L$ & $0.250 \pm 0.003^{\mathrm{Ba}}$ & $185.9 \pm 2.1^{\mathrm{Aa}}$ & $743.6^{\mathrm{Aa}}$ \\
\hline
\end{tabular}

$\alpha$, Photosynthetic efficiency measured by the initial slope of the RLC before the onset of saturation; rETR max, relative electron transport maximum; $E_{k}$, minimum saturating irradiance. Letters $A$ and $B$ indicate significant differences $(P<0.05)$ between treatments in the same genotype, while $a$ and $b$ indicate significant differences $(P<0.05)$ between genotypes under the same treatment.

negative control, but increased with increasing light intensity, especially in Z802 under HL. In general, $\mathrm{O}_{2}^{-}$radical accumulation was higher in Z802 compared to $\mathrm{pgl}$, suggesting photoinhibitory damage in leaves of Z802. This is consistent with the content of MDA, a marker of lipid peroxidation (Figure 9). SOD, CAT, and POD are responsible for the detoxification of $\mathrm{O}_{2}^{-}$and $\mathrm{H}_{2} \mathrm{O}_{2}$, thereby preventing the formation of superoxide radicals. SOD,
POD, and CAT activity increased in both Z802 and pgl under LL compared with HL. Activities of these enzymes suggest oxidative stresses under HL. Except for POD activity, both SOD and CAT activity were higher in $p g l$ than Z802 under HL, possibly due to the photo-oxidative damage in Z802.

\section{Thermal Imaging of the Rice Canopy and Midday Depression of Photosynthesis}

As shown in Figures 10, 11, nitrogen fertilizer significantly reduced the canopy temperature. The average canopy temperature of $\mathrm{Z} 802$ decreased from $32.1^{\circ} \mathrm{C}$ at $0 \mathrm{~N}$ to 31.6 and $31.1^{\circ} \mathrm{C}$ at 120 and $240 \mathrm{~N}$, respectively. In $p g l$, the average canopy temperature decreased from $32.7^{\circ} \mathrm{C}$ to 31.7 and $31.1^{\circ} \mathrm{C}$, respectively (Figures 10, 11). The temperature of the canopy differed between the two rice genotypes, regardless of $N$ inputs. The average canopy temperature was 0.9 and $0.6^{\circ} \mathrm{C}$ higher in pgl than Z802 in the morning (9:00) and afternoon (15:00), respectively, and $0.8^{\circ} \mathrm{C}$ lower at noon (13:00). The differences of canopy temperature at noon between genotype Z802 and $p g l$ were related to the different chlorophyll contents in Z08 and pgl. The chlorophyll contents in Z802 were $2.45,2.98$, and $3.34 \mathrm{mg}$ $\mathrm{g}^{-1} \mathrm{FW}$, at 0,120 , and $240 \mathrm{~N}$, respectively, while the chlorophyll 


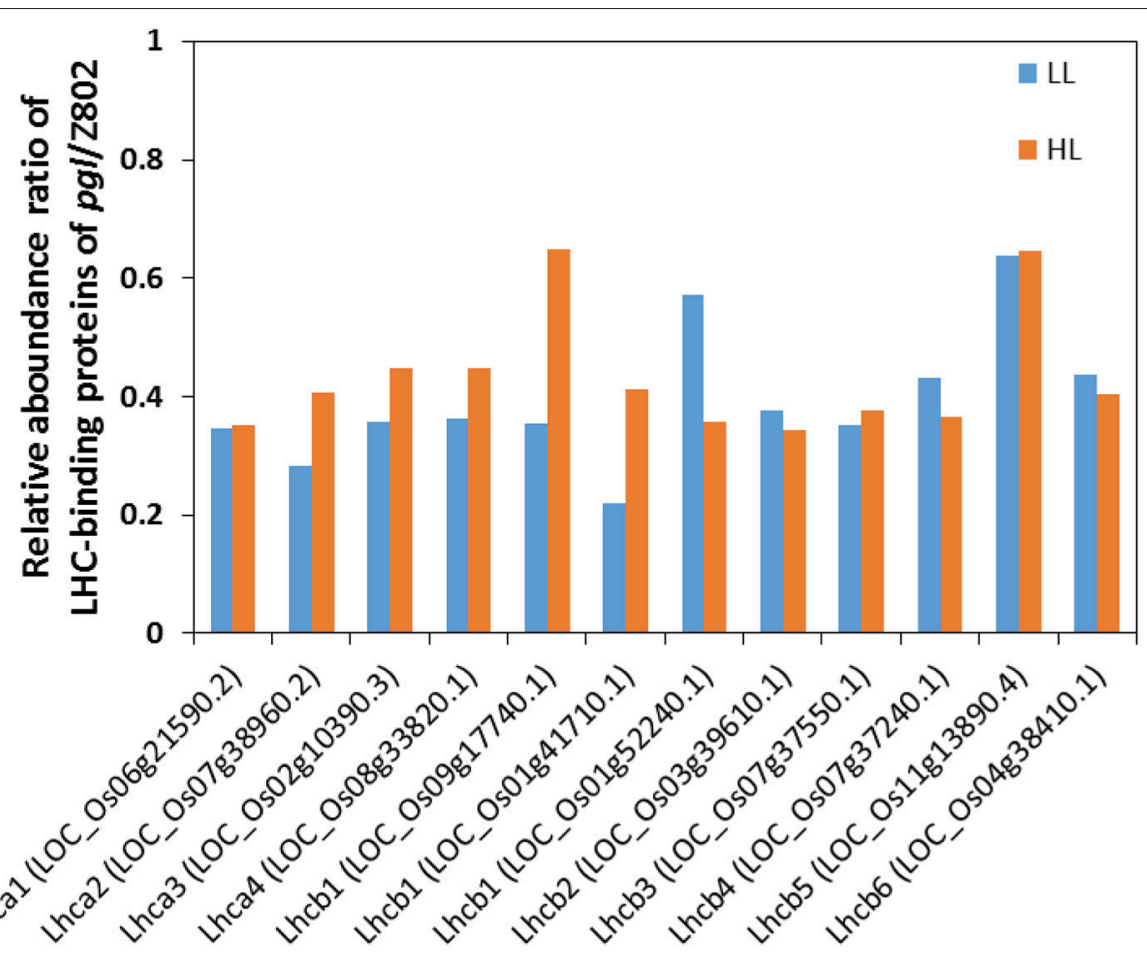

FIGURE 7 | The relative abundance of ratio of light harvesting complex ( $\mathrm{LHC}$ ) binding proteins of pgl/Z802 in low light (LL) and high light $(\mathrm{HL})$ treatments. The proteins of LHCI (Lhca1-4) and LHCll (Lhcb1-6) ligate chlorophylls and carotenes, which absorb light and transmit the excitation energy to the core complex.
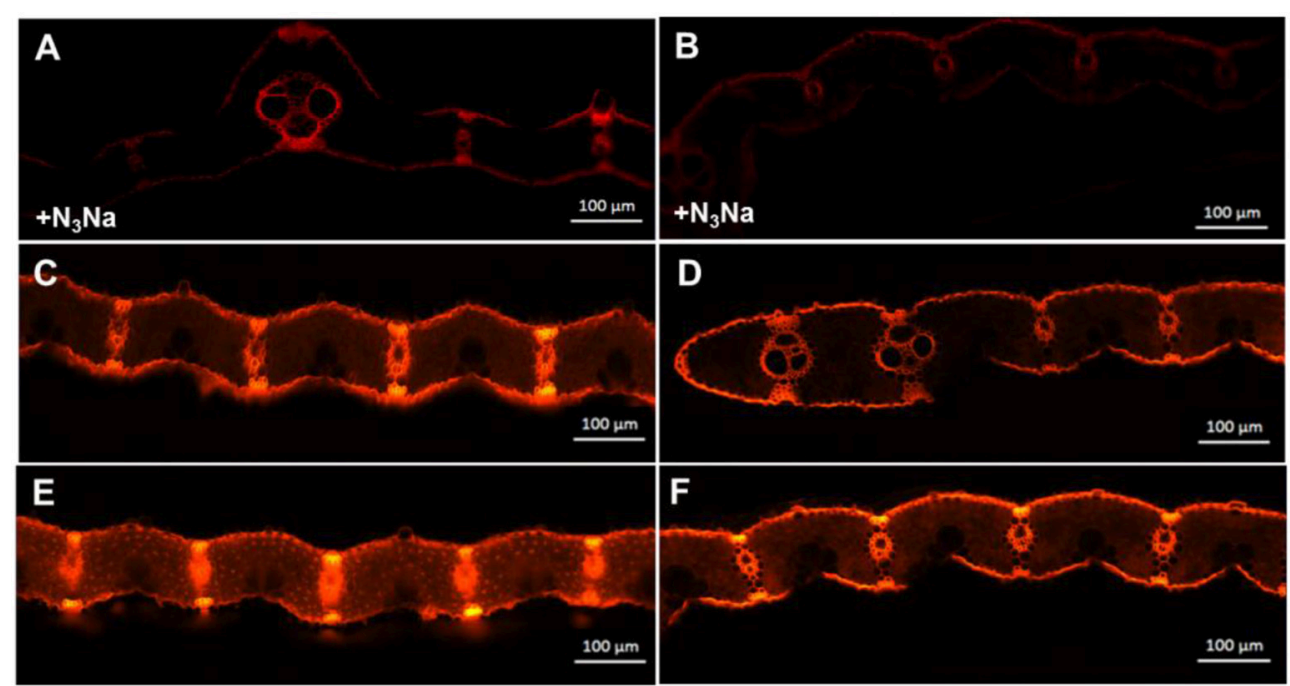

FIGURE 8 | Imaging of reactive oxygen species (ROS) in leaves of Z802 and pgl. $\mathrm{O}_{2}^{-}$-dependent DHE fluorescence in leaves of Z802 (A,C,E) and pgl (B,D,F). (A,B) As a negative control, leaf samples were incubated with $1 \mathrm{mM} \mathrm{N}_{3} \mathrm{Na}$ (peroxidase inhibitor). (C,D) Leaves under low light (PPFD: $\sim 200 \mu \mathrm{mol} \mathrm{m}^{-2} \mathrm{~s}^{-1}$ ) and (E,F) under high light $\left(\sim 1,000 \mu \mathrm{mol} \mathrm{m} \mathrm{m}^{-2} \mathrm{~s}^{-1}\right)$. Bars $=100 \mu \mathrm{m}$.

contents in $p g l$ were $1.38,1.47$, and $1.67 \mathrm{mg} \mathrm{g}^{-1} \mathrm{FW}$, at 0,120 , and $240 \mathrm{~N}$, respectively.

The canopy temperature is strongly correlated with midday depression of photosynthesis. The average photosynthetic rate decreased by 27.1 and $11.0 \%$ when comparing net photosynthesis at 13:00 and at 11:00 for Z802 and $p g l$, respectively (Figure 12). A particularly large drop in photosynthesis at noon was observed in Z802. This phenomenon of midday depression of photosynthesis was also strongly correlated with the higher canopy temperature at noon in Z802. 


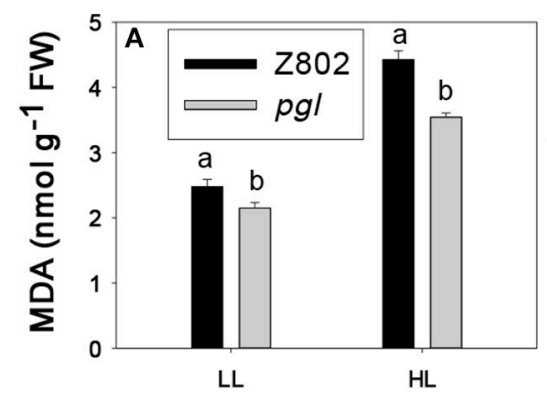

Light treatment

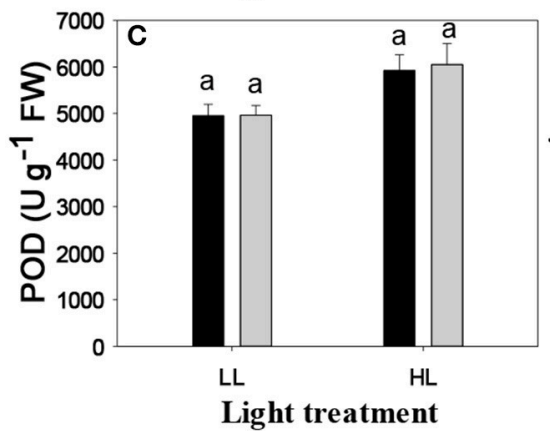

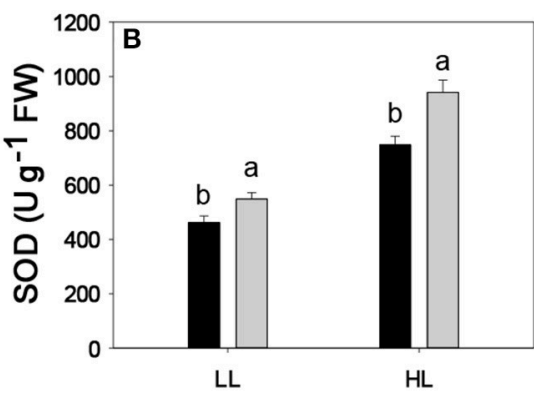

Light treatment



Light treatment

FIGURE 9 | Lipid peroxidation (MDA, A), and antioxidant enzymes activity (superoxide dismutase, SOD, B; peroxidase, POD, C; catalase, CAT, D) in leaves of Z802 and pgl under low $(\mathrm{LL})$ and high light treatment $(\mathrm{HL})$. Different letters indicate significant differences $(P<0.05)$ between genotypes at $L L$ or $H L$ treatment.

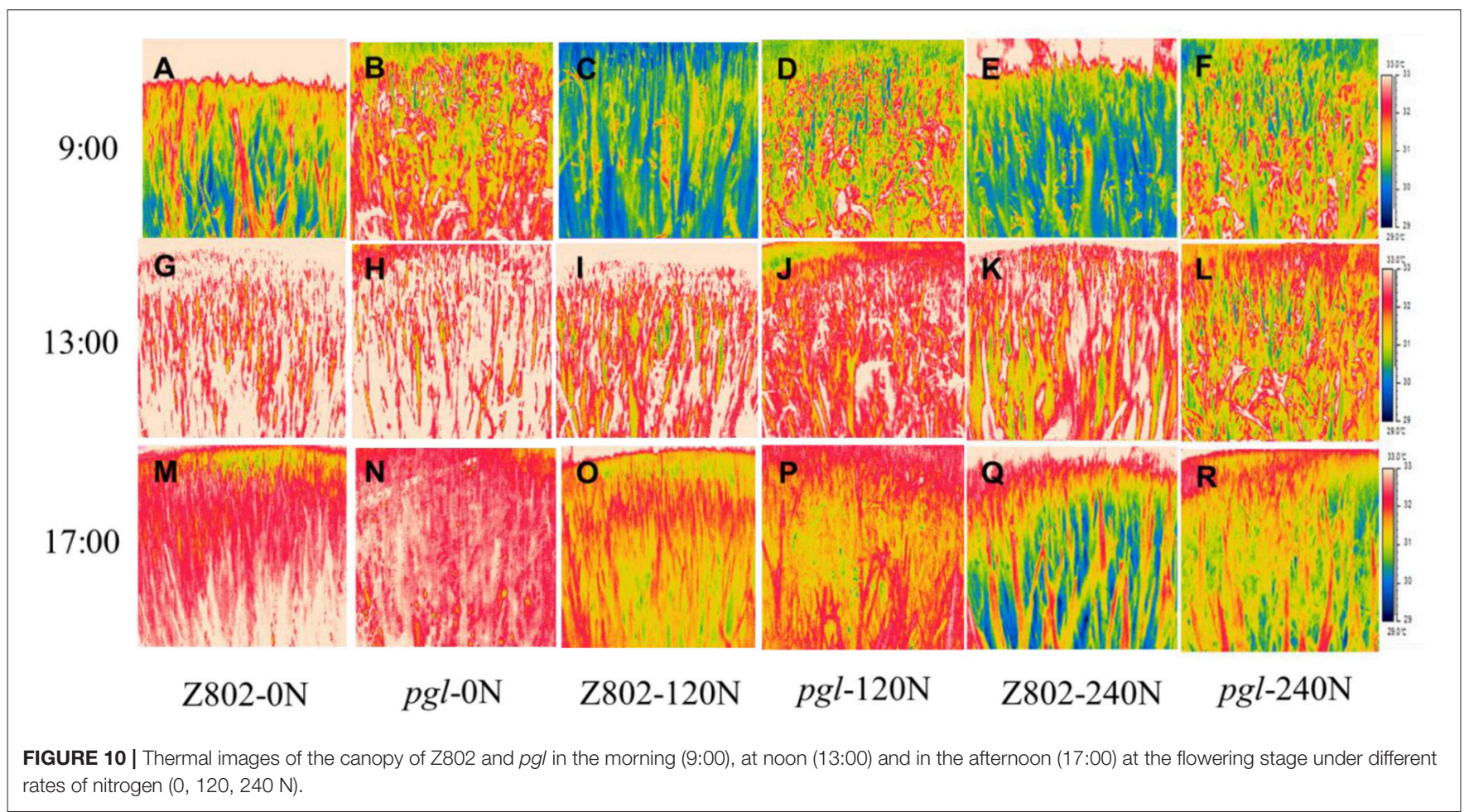

\section{DISCUSSION}

Plants tend to overinvest in the synthesis of chlorophyll, assembling a large array of chlorophyll antennae. These antennae consist of a large number of protein-bound chlorophyll molecules that absorb photons, transferring their energy to the photosynthesis reaction center (Melis, 2009). However, only a few of these chlorophyll molecules are constituents of the actual 


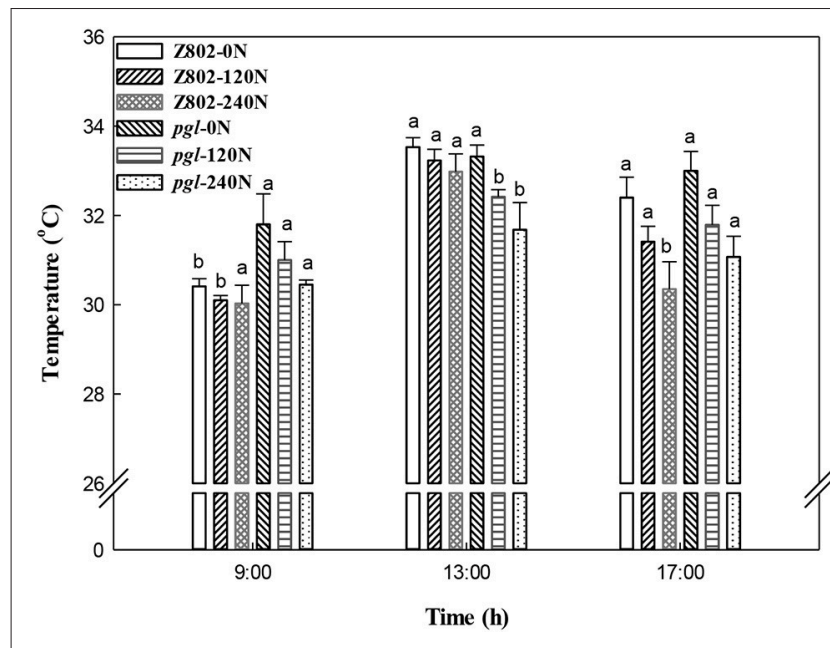

FIGURE 11 | Canopy temperatures of Z802 and pgl in the morning (9:00), at noon (13:00) and in the afternoon (17:00) under different rates of nitrogen (0, $120,240 \mathrm{~N})$. Vertical bars denote standard deviations $(n=10)$. Different letters indicate significant differences $(P<0.05)$ between genotypes at the same level of $\mathrm{N}$ and at the same time of day.

reaction centers, most remaining in the antennae. Oversized chlorophyll antennae ensure a selective advantage, allowing interception and absorption of more light than neighboring competitors, even more than is actually needed (Ort et al., 2011, 2015). Prevailing sunlight intensities are also much higher than that required for saturation of photosynthesis, resulting in over-excitation of the photosystems, induction of NPQ, and a decrease in solar energy conversion efficiency. We therefore speculated that a genotype with low chlorophyll content could improve solar conversion efficiency in rice, mitigating the effects of photoinhibitory damage, and allowing adaptation to the sunny high-temperature environments where rice grows.

Figure 6A shows the rates of electron transport plotted as a function of photosynthetic active photons ( $\mu \mathrm{mol}$ photons $\mathrm{m}^{-2}$ $\mathrm{s}^{-1}$ ). ETR linearly increased with increasing light intensity under a low light intensity range, suggesting that light absorption and light reactions, rather than carbon reactions, are limiting the photosystems (Gu et al., 2012a). Within this range of light intensities, photosynthesis operated at a maximum solar energy conversion efficiency. However, as light intensity increased, the slope of ETR decreased eventually approaching a plateau, the $r \mathrm{ETR}_{\max }$ (Table 1). This shows that a higher intensity of sunlight and increased absorption of solar photons does not translate into photosynthetic electron transport. Photosynthesis limitations are imposed either by the Calvin-Benson cycle (slow catalytic rate of Rubisco), or the bottleneck of electron transport through the cytochrome $b_{6} / f$ complex in the thylakoid membranes, or relatively slow turnover rate of the Mn-containing $\mathrm{H}_{2} \mathrm{O}$ oxidantion complex (Melis, 2009; Foyer and Shigeoka, 2011). As shown in Figure 6A, saturation of photosynthesis $\left(E_{k}\right)$ in Z802 was reached at $395.1 \mu \mathrm{mol}$ photons $\mathrm{m}^{-2} \mathrm{~s}^{-1}$ under LL and at $328.5 \mu \mathrm{mol} \mathrm{m}^{-2} \mathrm{~s}^{-1}$ under HL, and in $p g l$ at 631.0 and $743.6 \mu \mathrm{mol} \mathrm{m} \mathrm{m}^{-2} \mathrm{~s}^{-1}$, respectively. Taking into account the fact that sunlight intensities can reach up to $2,500 \mu \mathrm{mol} \mathrm{m} \mathrm{m}^{-2} \mathrm{~s}^{-1}$, these findings suggest that $\sim 85.5$ and $72.5 \%$ of the solar energy is wasted in Z802 and $p g l$, respectively, under high irradiance. The average $r E_{\text {ETR }}$ of $p g l$ was $173.4 \mu \mathrm{mol} \mathrm{e}^{-} \mathrm{m}^{-2} \mathrm{~s}^{-1}$, almost twice that of Z802 (Table 1), suggesting a higher capacity for photosynthesis. This is consistent with previous findings whereby higher photosynthetic activity was reported with low chlorophyll content in chlorophyll-deficient mutants of various plant species (Edwards et al., 1993; Habash et al., 1994; Havaux and Tardy, 1997; Li et al., 2013; Jin et al., 2016; Kirst et al., 2017; Slattery et al., 2017), algae (Melis et al., 1998; Polle et al., 2003), and cyanobacteria (Kirst et al., 2014).

Photosynthesis is an important source of cellular oxidants (Foyer and Shigeoka, 2011), with formation of triple chlorophylls (Hideg et al., 1998). By reacting with ground-state triplet oxygen, triple chlorophylls generate harmful singlet oxygen, which can cause cellular injury. Under moderate stress, plants appear to purposefully generate ROS as signaling molecules to control processes such as pathogen defense responses, programmed cell death, and stomatal behavior (Apel and Hirt, 2004; Pospíšil, 2016). However, when the energy absorbed by the photosystems exceeds the level that can be used by carbon fixation reactions and the scavenging system is unable to sufficiently eliminate undesirable ROS formation, oxidative damage of proteins, DNA, and lipids can occur (Apel and Hirt, 2004), as seen in Z802. For example, herbicides that inhibit the synthesis of carotenoids cause the production of vast amounts of ROS, which cause the chlorophyll to bleach and subsequently kill the plant (Wakabayashi and Böger, 2002). ROS inhibit the repair of PSII, in particular the synthesis of D1 protein, at the mRNA translation level (Nishiyama et al., 2006). As shown in Figure 8, more ROS accumulated in Z802 than pgl under HL, while as shown in Figure 4, more osmophilic bodies were observed in Z802 than pgl under HL. These findings suggest disruption of granum thylakoids and possible damage to the chloroplasts in Z802. Moreover, MDA, a sign of lipid peroxidation, was also higher in Z802 (Figure 9). Combined, these data suggest photoinhibitory damage in Z802, especially under HL. Leaves with low chlorophyll (i.e., $p g l$ ) produce less singlet oxygen under strong light compared to those with higher amounts of chlorophyll (Z802). Consequently, a pale leaf genotype is less prone to photo-oxidative damage of thylakoid membrane lipids and/or proteins (Tardy et al., 1998). This also explains why the two genotypes showed clearly distinctive patterns of chlorophyll content (Figure 2), light absorption (Figure 5), and RLC (Figure 6). Thus, in general, chloroplast development and photosynthesis were improved in the $p g l$ genotype under HL, while an opposite trend was found in Z802.

Under natural conditions of high temperature and intense sunlight, two net photosynthetic peaks occur, one in late morning and another in late afternoon, with a depression around noon, the so-called midday depression of photosynthesis (Figure 12). Excess light, in combination with a high leaf temperature, is the major environmental stress causing midday depression of photosynthesis (Valladares and Pearcy, 1997; Muraoka et al., 2000). Gu et al. (2012b) also found temperature to be a major factor limiting factor of photosynthesis under field conditions. Maintenance of a "low" leaf temperature at 



FIGURE 12 | Diurnal variation in the net photosynthetic rates of Z802 (A) and pgl (B) under different rates of nitrogen (0, $120,240 \mathrm{~N})$ at the flowering stage. Data represent the mean of four replicates with the standard deviation shown by vertical bars.

noon could therefore have important advantages in sunny environments, since photoinhibition of photosynthesis is temperature dependent, with elevated temperatures strongly exacerbating photoinhibition (Tardy et al., 1998).

In our experiment, the application of $\mathrm{N}$ fertilizer significantly decreased the canopy temperature as shown in Figure 11 and consistent with a previous study (Seligman et al., 1983). Maintaining a low concentration of chlorophyll in the leaf tissue is a general feature of plants that have genetically adapted to harsh environments (Maslova and Popova, 1993; Kyparissis et al., 1995; Tardy et al., 1998), which have been noted as the likely photoprotection mechanism mitigating the damaging effect of leaf heating in wild grasses and cereal landraces adapted to semiarid environments (Havaux and Tardy, 1999; Zaharieva et al., 2001; Royo et al., 2014; Ruíz et al., 2016). Similarly, in this study, the $p g l$ genotype with its lower chlorophyll content was also more resistant to the midday depression in photosynthesis (Figure 12) due to its cooler canopy (Figure 11).

\section{CONCLUSION}

Plants tend to overinvest in chlorophyll synthesis, with assembly of large chlorophyll antenna molecules in their photosynthetic apparatus. These large antennae absorb excess light energy relative to the capacity of the photosystems. This excess light energy subsequently results in the generation of high levels of ROS or is dissipated as heat by NPQ. It is therefore a waste of energy, thereby decreasing the solar energy conversion efficiency. In this study, however, the $p g l$ genotype with truncated light-harvesting chlorophyll antenna showed a low level of NPQ and ROS generation. Photosystem II efficiency and ETR were also high in the $p g l$ genotype. Combined, these data indicate that selecting of a rice genotype with a low chlorophyll content could improve solar conversion efficiency,

\section{REFERENCES}

Aebi, H. (1983). "Catalase," in Methods of Enzymatic Analysis, ed H. U. Bergmeyer (New York, NY: Academic Press), 273-288. mitigating the effects of photoinhibitory damage and improving adaptation to the sunny high-temperature environments where rice grows. Although, the physiological mechanisms were discussed, the genetic basis remains obscure and requires further studies. Furthermore, physiological studies, especially quantitative proteomics studies should combined with modeling analyses (Friend, 1991; Hikosaka and Terashima, 1995; Medlyn, 1996; Hikosaka, 1997, 2005; Xu et al., 2012) to reveal how large and what ratio of light harvesting complexes among the photosystems are optimal for the efficiency of photosynthesis.

\section{AUTHOR CONTRIBUTIONS}

JG, JY designed the research. JG, ZZ, ZL, YC, ZW, and HZ performed research. JG, ZZ, and JY analyzed the data. JG, ZZ, and JY wrote the paper.

\section{ACKNOWLEDGMENTS}

This work was financially supported by the National Basic Research Program of China (973 Program) [grant number 2015CB150400], the National Natural Science Foundation of China [grant numbers 31501254, 31461143015], the Natural Science Foundation of Jiangsu Province, China [grant number BK20140480], the Priority Academic Program Development of Jiangsu Higher Education Institutions (PAPD), and the Top Talent Supporting Program of Yangzhou University.

\section{SUPPLEMENTARY MATERIAL}

The Supplementary Material for this article can be found online at: http://journal.frontiersin.org/article/10.3389/fpls.2017. 01082/full\#supplementary-material

Apel, K., and Hirt, H. (2004). Reactive oxygen species: metabolism, oxidative stress, and signal transduction. Annu. Rev. Plant Biol. 55, 373-399. doi: 10.1146/annurev.arplant.55.031903.1 41701 
Bilger, W., and Björkman, O. (1990). Role of the xanthophyll cycle in photoprotection elucidated by measurements of light-induced absorbance changes, fluorescence and photosynthesis in leaves of Hedera canariensis. Photosynth. Res. 25, 173-185. doi: 10.1007/BF00033159

Chance, B., and Maehly, A. C. (1955). Assay of catalases and peroxidases. Methods Enzymol. 2, 764-775. doi: 10.1016/S0076-6879(55)02300-8

Cui, L. L., Lu, Y. S., Li, Y., Yang, C., and Peng, X. X. (2016). Overexpression of glycolate oxidase confers improved photosynthesis under high light and high temperature in rice. Front. Plant Sci. 7:1165. doi: 10.3389/fpls.2016.01165

de Groot, H. (2008). "Harnessing solar energy for the production of clean fuels," in 40 Years Theory and Model at Wageningen UR-on the Occasion of the 40th Anniversary of the Inaugural Address of C.T. de Wit in 1968, eds H. van Keulen, H. H. van Laar, and R. Rabbinge (Wageningen: Wageningen University and Research Centre), 5-7.

Dhindsa, R. S., Plumb-dhindsa, P., and Thorpe, T. A. (1981). Leaf senescence: correlated with increased levels of membrane permeability and lipid peroxidation, and decreased levels of superoxide dismutase and catalase. J. Exp. Bot. 32, 93-101. doi: 10.1093/jxb/32.1.93

Edwards, G. E., Johnson, E., Lal, A., and Krall, J. P. (1993). Quantum yields of photosystem II and photosynthesis in a Aurea mutant of tobacco (C3) and an oil yellow mutant of maize (C4) which have high capacities for photosynthesis despite low chlorophyll contents. Plant Cell Physiol. 34, 1205-1212.

Foyer, C. H., and Noctor, G. (2009). Redox regulation in photosynthetic organisms: signaling, acclimation, and practical implications. Antioxid. Redox Sign. 11, 861-905. doi: 10.1089/ars.2008.2177

Foyer, C. H., and Shigeoka, S. (2011). Understanding oxidative stress and antioxidant functions to enhance photosynthesis. Plant Physiol. 155, 93-100. doi: 10.1104/pp.110.166181

Friend, A. D. (1991). Use of a model of photosynthesis and leaf microenvironment to predict optimal stomatal conductance and leaf nitrogen partitioning. Plant Cell Environ. 14, 895-905. doi: 10.1111/j.1365-3040.1991.tb00958.x

Furbank, R. T., Quick, W. P., and Sirault, X. R. R. (2015). Improving photosynthesis and yield potential in cereal crops by targeted genetic manipulation: prospects, progress and challenges. Field Crop Res. 182, 19-29. doi: 10.1016/j.fcr.2015.04.009

Genty, B., Briantais, J. M., and Baker, N. R. (1989). The relationship between the quantum yield of photosynthetic electron transport and quenching of chlorophyll fluorescence. Biochim. Biophys. Acta 990, 87-92. doi: $10.1016 /$ S0304-4165(89)80016-9

Giannopolitis, C. N., and Ries, S. K. (1977). Superoxide dismutases: I. Occurrence in higher plants. Plant Physiol. 59, 309-314. doi: 10.1104/pp.59.2.309

Gu, J., Yin, X., Stomph, T. J., and Struik, P. C. (2014). Can exploiting natural genetic variation in leaf photosynthesis contribute to increasing rice productivity? A simulation analysis. Plant Cell Environ. 37, 22-34. doi: 10.1111/pce.12173

Gu, J., Yin, X., Stomph, T. J., Wang, H., and Struik, P. C. (2012a). Physiological basis of genetic variation in leaf photosynthesis among rice (Oryza sativa L.) introgression lines under drought and well-watered conditions. J. Exp. Bot. 63, 5137-5153. doi: 10.1093/jxb/ers170

Gu, J., Yin, X., Struik, P. C., Stomph, T. J., and Wang, H. (2012b). Using chromosome introgression lines to map quantitative trait loci for photosynthesis parameters in rice (Oryza sativa L.) leaves under drought and well watered field conditions. J. Exp. Bot. 63, 455-469. doi: 10.1093/jxb/e rr292

Gu, J., Zhou, Z., Li, Z., Chen, Y., Wang, Z., and Zhang, H. (2017). Rice (Oryza sativa L.) with reduced chlorophyll content exhibit higher photosynthetic rate and efficiency, improved canopy light distribution, and greater yields than normally pigmented plants. Field Crop Res. 200, 58-70. doi: 10.1016/j.fcr.2016.10.008

Habash, D. Z., Genty, B., and Baker, N. R. (1994). The consequences of chlorophyll deficiency for photosynthetic light use efficiency in a single nuclear gene mutation of cowpea. Photosynth. Res. 42, 17-25. doi: 10.1007/BF00019054

Harrison, W. G., and Platt, T. (1986). Photosynthesis-irradiance relationships in polar and temperate phytoplankton populations. Polar Biol. 5, 153-164. doi: $10.1007 /$ BF00441695

Havaux, M., and Tardy, F. (1997). Thermostability and photostability of photosystem II in leaves of the chlorine-f2 brley mutant deficient in lightharvesting chlorophyll a/b protein complexes. Plant Physiol. 113, 913-923. doi: $10.1104 /$ pp.113.3.913
Havaux, M., and Tardy, F. (1999). Loss of chlorophyll with limited reduction of photosynthesis as an adaptive response of Syrian barley landraces to high-light and heat stress. Funct. Plant Biol. 26, 569-578. doi: 10.1071/pp99046

Henley, W. J. (1993). Measurement and interpretation of photosynthetic lightresponse curves in algae in the context of photoinhibition and diel changes. J. Phycol. 29, 729-739. doi: 10.1111/j.0022-3646.1993.00729.x

Hideg, E., Kálai, T., Hideg, K., and Vass, I. (1998). Photoinhibition of photosynthesis in vivo results in singlet oxygen production detection via nitroxide-induced fluorescence quenching in broad bean leaves. Biochemistry 37, 11405-11411. doi: 10.1021/bi972890+

Hikosaka, K. (1997). Modelling optimal temperature acclimation of the photosynthetic apparatus in $\mathrm{C} 3$ plants with respect to nitrogen use. Ann. Bot. London 80, 721-730. doi: 10.1006/anbo.1997.0512

Hikosaka, K. (2005). Nitrogen partitioning in the photosynthetic apparatus of Plantago asiatica leaves grown under different temperature and light conditions: similarities and differences between temperature and light acclimation. Plant Cell Physiol. 46, 1283-1290. doi: 10.1093/pcp/pci137

Hikosaka, K., and Terashima, I. (1995). A model of the acclimation of photosynthesis in the leaves of C3 plants to sun and shade with respect to nitrogen use. Plant Cell Environ. 18, 605-618. doi: 10.1111/j.1365-3040.1995.tb00562.x

Jin, H., Li, M., Duan, S., Fu, M., Dong, X., Liu, B., et al. (2016). Optimization of light-harvesting pigment improves photosynthetic efficiency. Plant Physiol. 172, 1720-1731. doi: 10.1104/pp.16.00698

Kirst, H., Formighieri, C., and Melis, A. (2014). Maximizing photosynthetic efficiency and culture productivity in cyanobacteria upon minimizing the phycobilisome light-harvesting antenna size. Biochim. Biophys. Acta 1837, 1653-1664. doi: 10.1016/j.bbabio.2014.07.009

Kirst, H., Gabilly, S. T., Niyogi, K. K., Lemaux, P. G., and Melis, A. (2017). Photosynthetic antenna engineering to improve crop yields. Planta 245, 1009-1020. doi: 10.1007/s00425-017-2659-y

Krieger-Liszkay, A., Fufezan, C., and Trebst, A. (2008). Singlet oxygen production in photosystem II and related protection mechanism. Photosynth. Res. 98, 551-564. doi: 10.1007/s11120-008-9349-3

Kyparissis, A., Petropoulou, Y., and Manetas, Y. (1995). Summer survival of leaves in a soft-leaved shrub (Phlomis fruticosa L., Labiatae) under mediterranean field conditions: avoidance of photoinhibitory damage through decreased chlorophyll contents. J. Exp. Bot. 46, 1825-1831. doi: 10.1093/jxb/46.12.1825

Li, Y., Ren, B., Gao, L., Ding, L., Jiang, D., Xu, X., et al. (2013). Less chlorophyll does not necessarily restrain light capture ability and photosynthesis in a chlorophyll-deficient rice mutant. J. Agron. Crop Sci. 199, 49-56. doi: 10.1111/j.1439-037X.2012.00519.x

Long, S. P., Marshall-Colon, A., and Zhu, X. (2015). Meeting the global food demand of the future by engineering crop photosynthesis and yield potential. Cell 161, 56-66. doi: 10.1016/j.cell.2015.03.019

Long, S. P., Zhu, X., Naidu, S. L., and Ort, D. R. (2006). Can improvement in photosynthesis increase crop yields? Plant Cell Environ. 29, 315-330. doi: 10.1111/j.1365-3040.2005.01493.x

Macpherson, A. N., Telfer, A., Barber, J., and Truscott, T. G. (1993). Direct detection of singlet oxygen from isolated photosystem II reaction centers. Biochim. Biophys. Acta 1143, 301-309. doi: 10.1016/0005-2728(93)90201-P

Maslova, T. G., and Popova, I. A. (1993). Adaptive properties of the plant pigment systems. Photosynthetica 29, 195-203.

Maurino, V. G., and Peterhansel, C. (2010). Photorespiration: current status and approaches for metabolic engineering. Curr. Opin. Plant Biol. 13, 248-255. doi: 10.1016/j.pbi.2010.01.006

Medlyn, B. E. (1996). The optimal allocation of nitrogen within the C3 photosynthetic system at elevated CO2. Aust. J. Plant Physiol. 23, 593-603. doi: 10.1071/PP9960593

Melis, A. (1999). Photosystem-II damage and repair cycle in chloroplasts: what modulates the rate of photodamage in vivo? Trends Plant Sci. 4, 130-135. doi: 10.1016/S1360-1385(99)01387-4

Melis, A. (2009). Solar energy conversion efficiencies in photosynthesis: minimizing the chlorophyll antennae to maximize efficiency. Plant Sci. 177, 272-280. doi: 10.1016/j.plantsci.2009.06.005

Melis, A., Neidhardt, J., and Benemann, J. R. (1998). Dunaliella salina (Chlorophyta) with small chlorophyll antenna sizes exhibit higher 
photosynthetic productivities and photon use efficiencies than normally pigmented cells. J. Appl. Phycol. 10, 515-525. doi: 10.1023/A:1008076231267

Miyake, C., Miyata, M., Shinzaki, Y., and Tomizawa, K. (2005). CO2 response of cyclic electron flow around PSI (CEF-PSI) in tobacco leaves - relative electron fluxes through PSI and PSII determine the magnitude of nonphotochemical quenching (NPQ) of Chl fluorescence. Plant Cell Physiol. 46, 629-637. doi: 10.1093/pcp/pci067

Mueller-Cajar, O., and Whitney, S. M. (2008). Directing the evolution of Rubisco and Rubisco activase: first impressions of a new tool for photosynthesis research. Photosynth. Res. 98, 667-675. doi: 10.1007/s11120-008-9324-z

Muraoka, H., Tang, Y., Terashima, I., Koizumi, H., and Washitani, I. (2000). Contributions of diffusional limitation, photoinhibition and photorespiration to midday depression of photosynthesis in Arisaema heterophyllum in natural high light. Plant Cell Environ. 23, 235-250. doi: 10.1046/j.1365-3040.2000.00547.x

Nishiyama, Y., Allakhverdiev, S. I., and Murata, N. (2006). A new paradigm for the action of reactive oxygen species in the photoinhibition of photosystem II. Biochim. Biophys. Acta 1757, 742-749. doi: 10.1016/j.bbabio.2006.05.013

Niyogi, K. K. (2000). Safety valves for photosynthesis. Curr. Opin. Plant Biol. 3, 455-460. doi: 10.1016/S1369-5266(00)00113-8

Niyogi, K. K., Grossman, A. R., and Björkman, O. (1998). Arabidopsis mutants define a central role for the xanthophyll cycle in the regulation of photosynthetic energy conversion. Plant Cell 10, 1121-1134. doi: $10.1105 /$ tpc.10.7.1121

Ort, D. R., Merchant, S. S., Alric, J., Barkan, A., Blankenship, R. E., Bock, R., et al. (2015). Redesigning photosynthesis to sustainably meet global food and bioenergy demand. Proc. Natl. Acad. Sci. U.S.A. 112, 8529-8536. doi: 10.1073/pnas.1424031112

Ort, D. R., Zhu, X., and Melis, A. (2011). Optimizing antenna size to maximize photosynthetic efficiency. Plant Physiol. 155, 79-85. doi: $10.1104 /$ pp. 110.165886

Pettigrew, W., Hesketh, J., Peters, D., and Woolley, J. (1989). Characterization of canopy photosynthesis of chlorophyll-deficient soybean isolines. Crop Sci. 29, 1025-1029. doi: 10.2135/cropsci1989.0011183X002900040040x

Platt, T., Gallegos, C. L., and Harrison, W. G. (1980). Photoinhibition of photosynthesis in natural assemblages of marine phytoplankton. J. Mar. Res. $38,687-701$.

Polle, J. E., Kanakagiri, S. D., and Melis, A. (2003). tla1, a DNA insertional transformant of the green alga Chlamydomonas reinhardtii with a truncated light-harvesting chlorophyll antenna size. Planta 217, 49-59. doi: 10.1007/s00425-002-0968-1

Pospísil, P. (2016). Production of reactive oxygen species by photosystem II as a response to light and temperature stress. Front. Plant Sci. 7:1950. doi: $10.3389 /$ fpls.2016.01950

Ralph, P. J., and Gademann, R. (2005). Rapid light curves: a powerful tool to assess photosynthetic activity. Aquat. Bot. 82, 222-237. doi: 10.1016/j.aquabot.2005.02.006

Ray, D. K., Mueller, N. D., West, P. C., and Foley, J. A. (2013). Yield trends are insufficient to double global crop production by 2050. PLoS ONE 8:e66428. doi: 10.1371 /journal.pone. 0066428

Rodríguez-Serrano, M., Romero-Puertas, M. C., Zabalza, A., Corpas, F. J., Gómez, M., Del Río, L. A., et al. (2006). Cadmium effect on oxidative metabolism of pea (Pisum sativum L.) roots. Imaging of reactive oxygen species and nitric oxide accumulation in vivo. Plant Cell Environ. 29, 1532-1544. doi: 10.1111/j.1365-3040.2006.01531.x

Royo, C., Nazco, R., and Villegas, D. (2014). The climate of the zone of origin of Mediterranean durum wheat (Triticum durum Desf.) landraces affects their agronomic performance. Genet. Resour. Crop Evol. 61, 1345-1358. doi: $10.1007 / \mathrm{s} 10722-014-0116-3$

Ruíz, M., Quemada, M., García, R., Carrillo, J., and Benaventa, E. (2016). Use of thermographic imaging to screen for drought-tolerant genotypes in Brachypodium distachyon. Crop Pasture Sci. 67, 99-108. doi: 10.1071/CP15134

Seligman, N. G., Loomis, R. S., Burke, J., and Abshahi, A. (1983). Nitrogen nutrition and canopy temperature in field-grown spring wheat. J. Agric. Sci. 101, 691-697. doi: 10.1017/S0021859600038727

Slattery, R. A., VanLoocke, A., Bernacchi, C. J., Zhu, X., and Ort, D. R. (2017). Photosynthesis, light use efficiency, and yield of reduced-chlorophyll soybean mutants in field conditions. Front. Plant Sci. 8:549. doi: 10.3389/fpls.2017. 00549
Tardy, F., Créach, A., and Havaux, M. (1998). Photosynthetic pigment concentration, organization and interconversions in a pale green Syrian landrace of barley (Hordeum vulgare L., Tadmor) adapted to harsh climatic conditions. Plant Cell Environ. 21, 479-489. doi: $10.1046 /$ j.1365-3040.1998.00293.x

Telfer, A. (2014). Singlet oxygen production by PSII under light stress: mechanism, detection and the protective role of $\beta$-carotene. Plant Cell Physiol. 55, 1216-1223. doi: 10.1093/pcp/pcu040

Uehlein, N., Otto, B., Hanson, D. T., Fischer, M., McDowell, N., and Kaldenhoff, R. (2008). Function of Nicotiana tabacum aquaporins as chloroplast gas pores challenges the concept of membrane CO2 permeability. Plant Cell 20, 648-657. doi: $10.1105 /$ tpc. 107.054023

Valladares, F., and Pearcy, R. W. (1997). Interactions between water stress, sun-shade acclimation, heat tolerance and photoinhibition in the sclerophyll Heteromeles arbutifolia. Plant Cell Environ. 20, 25-36. doi: 10.1046/j.1365-3040.1997.d01-8.x

Vass, I., and Cser, K. (2009). Janus-faced charge recombinations in photosystem II photoinhibition. Trends Plant Sci. 14, 200-205. doi: $10.1016 /$ j.tplants.2009.01.009

von Caemmerer,. S., Quick, W. P., and Furbank, R. T. (2012). The development of C4 rice: current progress and future challenges. Science 336, 1671-1672. doi: $10.1126 /$ science. 1220177

Wakabayashi, K., and Böger, P. (2002). Target sites for herbicides: entering the 21st century. Pest Manag. Sci. 58, 1149-1154. doi: 10.1002/ps.560

Whitney, S. M., and Sharwood, R. E. (2008). Construction of a tobacco master line to improve Rubisco engineering in chloroplasts. J. Exp. Bot. 59, 1909-1921. doi: $10.1093 / \mathrm{jxb} / \mathrm{erm} 311$

Xu, C., Fisher, R., Wullschleger, S. D., Wilson, C. J., Cai, M., and McDowell, N. G. (2012). Toward a mechanistic modeling of nitrogen limitation on vegetation dynamics. PLoS ONE 7:e37914. doi: 10.1371/journal.pone.0037914

Yamamoto, Y., Kobayashi, Y., Devi, R. S., Rikiishi, S., and Matsumoto, H. (2002). Aluminum toxicity is associated with mitochondrial dysfunction and the production of reactive oxygen species in plant cells. Plant Physiol. 128, 63-72. doi: $10.1104 /$ pp.010417

Yamori, W., and Shikanai, T. (2016). Physiological functions of cyclic electron transport around photosystem I in sustaining photosynthesis and plant growth. Annu. Rev. Plant Biol. 67, 81-106. doi: 10.1146/annurev-arplant-043015-112002

Yin, X., and Struik, P. C. (2015). Constraints to the potential efficiency of converting solar radiation into phytoenergy in annual crops: from leaf biochemistry to canopy physiology and crop ecology. J. Exp. Bot. 66, 6535-6549. doi: 10.1093/jxb/erv371

Yu, T., Li, G., Dong, S., Liu, P., Zhang, J., and Zhao, B. (2016). Proteomic analysis of maize grain development using iTRAQ reveals temporal programs of diverse metabolic processes. BMC Plant Biol. 16:241. doi: 10.1186/s12870-016-0878-1

Zaharieva, M., Gaulin, E., Havaux, M., Acevedo, E., and Monneveux, P. (2001). Drought and heat responses in the wild wheat relative Aegilops geniculata Roth: potential interest for wheat improvement. Crop Sci. 41, 1321-1329. doi: $10.2135 /$ cropsci2001.4141321x

Zhao, H., Kalivendi, S., Zhang, H., Joseph, J., Nithipatikom, K., Vázquez-Vivar, J., et al. (2003). Superoxide reacts with hydroethidine but forms a fluorescent product that is distinctly different from ethidium: potential implications in intracellular fluorescence detection of superoxide. Free Radic. Biol. Med. 34, 1359-1368. doi: 10.1016/S0891-5849(03)00142-4

Conflict of Interest Statement: The authors declare that the research was conducted in the absence of any commercial or financial relationships that could be construed as a potential conflict of interest.

The reviewer HM and handling Editor declared their shared affiliation, and the handling Editor states that the process met the standards of a fair and objective review.

Copyright $\odot 2017 \mathrm{Gu}$, Zhou, Li, Chen, Wang, Zhang and Yang. This is an open-access article distributed under the terms of the Creative Commons Attribution License (CC $B Y$ ). The use, distribution or reproduction in other forums is permitted, provided the original author(s) or licensor are credited and that the original publication in this journal is cited, in accordance with accepted academic practice. No use, distribution or reproduction is permitted which does not comply with these terms. 